present with a range of both typical and/or atypical symptoms, outside those included the current case definition for COVID-19 $19^{1-3,7}$ Additionally, in this study, some individuals developed symptoms up to 1 week after they tested positive for SARS-CoV-2. During this time, individuals may have the potential to transmit the virus unknowingly to others, which may have devastating impacts in high-risk settings such as care homes. Therefore, it is critical that all residents and staff are tested in an outbreak situation to identify COVID-19 asymptomatic and presymptomatic individuals who could transmit SARS-CoV-2 before significant symptoms develop. Once it is known that someone has the infection, particularly in a care-home setting, strict infection control measures are required to contain the spread of infection. During this study, once an outbreak had been confirmed, this was managed in line with the existing public health guidance for outbreaks in a care home.

In conclusion, the findings of this study emphasize the need to identify residents and staff with atypical symptoms and to identify asymptomatic residents and staff through comprehensive and regular screening for SARS-CoV-2.

Acknowledgments.

Financial support. No financial support was provided relevant to this article.
Conflicts of interest. All authors report no conflicts of interest relevant to this article.

\section{References}

1. Arons MM, Hatfield KM, Public Health-Seattle and King County and CDC COVID-19 Investigation Team. Presymptomatic SARS-CoV-2 infections and transmission in a skilled nursing facility. N Engl J Med 2020;382: 2081-2090.

2. McMichael TM, Currie DW, Public Health-Seattle and King County, EvergreenHealth, and CDC COVID-19 Investigation Team. Epidemiology of COVID-19 in a long-term care facility in King County, Washington. N Engl J Med 2020;382:2005-2011.

3. Sakurai A, Sasaki T, Kato S, et al. Natural history of asymptomatic SARS-CoV-2 infection. N Engl J Med 2020;383:885-886.

4. Akner G. Analysis of multimorbidity in individual elderly nursing home residents. Development of a multimorbidity matrix. Arch Gerontol Geriatr 2009;49:413-419.

5. Atkins JL, Masoli JAH, Delgado J, et al. Preexisting comorbidities predicting COVID-19 and mortality in the UK Biobank Community Cohort. J Gerontol A Biol Sci Med Sci 2020. doi: 10.1093/gerona/glaa183.

6. Rawle MJ, Bertfield DL, Brill SE. Atypical presentations of COVID-19 in care home residents presenting to secondary care: a UK single centre study. Preprint. Aging Med 2020. doi: 10.1002/agm2.12126.

7. Graham NSN, Junghans C, Downes R, et al. SARS-CoV-2 infection, clinical features and outcome of COVID-19 in United Kingdom nursing homes. J Infect 2020;81:411-419.

\title{
Dealing with coronavirus disease 2019 (COVID-19) outbreaks in long-term care homes: A protocol for room moving and cohorting
}

\author{
Dylan C. Kain $\mathrm{MD}^{1}$, Liz J. McCreight $\mathrm{BSc}^{2}$ and Jennie Johnstone MD, $\mathrm{PhD}^{2,3,4}$ \\ ${ }^{1}$ Department of Medicine, University of Toronto, Toronto, Canada, ${ }^{2}$ Infection Prevention and Control, Sinai Health, Toronto, Canada, ${ }^{3}$ Department of Laboratory \\ Medicine and Pathobiology, University of Toronto, Toronto, Canada and ${ }^{4}$ Dalla Lana School of Public Health, University of Toronto, Toronto, Canada
}

To the Editor-As coronavirus disease 2019 (COVID-19) has swiftly moved across the world, it has had an especially large impact in long-term care homes, with many countries reporting $>50 \%$ of COVID-19 related deaths due to outbreaks in long-term care home. ${ }^{1}$ Outbreaks in these homes can rapidly spread with high mortality, ${ }^{2}$ and homes with multiple residents per room have been forced to move residents within the home to slow and prevent further spread. Such movements may contribute to the larger impact of COVID-19 in homes with increased multiple-bed rooms. ${ }^{3}$ In most long-term care homes, moving people from their room within the home for the purpose of infection control was a completely novel concept. Consequently, those responsible for these room movements often did not have experience with this

Author for correspondence: Dr Jennie Johnstone, E-mail: jennie.johnstone@ sinaihealth.ca

Cite this article: Kain DC, McCreight LJ, and Johnstone J. (2021). Dealing with coronavirus disease 2019 (COVID-19) outbreaks in long-term care homes: A protocol for room moving and cohorting. Infection Control \& Hospital Epidemiology, 42: 1402-1403, https://doi.org/10.1017/ice.2020.1302 type of movement. To our knowledge, no existing guidance on principles of room movement is available for long-term care homes for the purposes of infection control. ${ }^{4}$

When our infection control team was partnered with several long-term care homes across the Toronto area, we identified this knowledge gap and worked to create a guidance with the goal of providing a tool to help homes with multiple-bed rooms work through logical moves to reduce the risk of COVID-19 transmission (Table 1). Priority of resident moves and cohorting are a key consideration because homes often have limited space. In an outbreak, cleaning staff may not be able to clean rooms at the pace needed to make all room moves simultaneously. Having a better understanding of principles of room movement during a COVID-19 outbreak setting may help minimize the size and scale of the outbreaks in the first wave.

As we prepare for a second wave of disease in many countries, having clear guidance for homes on ways to safely move residents is critical to preventing such large-scale outbreaks. We hope this guidance will serve as a template for long-term care homes moving forward.

(c) The Author(s), [year]. Published by Cambridge University Press on behalf of The Society for Healthcare Epidemiology of America. This is an Open Access article, distributed under the terms of the Creative Commons Attribution licence (http://creativecommons.org/licenses/by/4.0/), which permits unrestricted re-use, distribution, and reproduction in any medium, provided the original work is properly cited. 
Table 1. Principals of Room Movements in Long-Term Care Homes During the COVID-19 Pandemic

\begin{tabular}{|c|}
\hline Steps After Identifying a Symptomatic Resident \\
\hline $\begin{array}{l}\text { 1. Immediately move the symptomatic resident }{ }^{5} \text { to a private room on } \\
\text { precautions for COVID-19a and place the remaining residents that have } \\
\text { been exposed on precautions for COVID-19. If possible move each exposed } \\
\text { resident to their own private room; if not feasible, keep the exposed } \\
\text { residents within the room, and maintain precautions at the bedside. }\end{array}$ \\
\hline $\begin{array}{l}\text { 2. At a minimum test the symptomatic resident as well as the exposed } \\
\text { roommates for COVID-19. }\end{array}$ \\
\hline $\begin{array}{l}\text { 3. In the event any of the test results are positive for COVID-19, all exposed } \\
\text { residents must be on appropriate precautions for } 14 \text { days from their last } \\
\text { exposure to the positive resident. Ideally residents exposed to a positive } \\
\text { resident will be moved to a private room, regardless of their RT-PCR } \\
\text { results. }\end{array}$ \\
\hline $\begin{array}{l}\text { 4. A diagnosis of COVID-19 in a resident of a home, should prompt } \\
\text { consideration of a COVID-19 outbreak. Further testing and suspected } \\
\text { outbreak measures should be implemented at the direction of public } \\
\text { health authorities. }\end{array}$ \\
\hline Guideline for Cohorting Residents \\
\hline $\begin{array}{l}\text { 1. The fewest room moves possible should be made that ensure safety } \\
\text { of residents. Movement is labor intensive; it generates possible risk } \\
\text { of exposure; and it can distress residents. }\end{array}$ \\
\hline $\begin{array}{l}\text { 2. Asymptomatic exposed residents without confirmed COVID-19 should } \\
\text { never be isolated in a cohort together. }{ }^{\text {b }}\end{array}$ \\
\hline $\begin{array}{l}\text { 3. Residents with confirmed COVID-19 during the same outbreak can be } \\
\text { cohorted together if necessary, to allow cleaning and freeing additional } \\
\text { space within the home. }\end{array}$ \\
\hline $\begin{array}{l}\text { 4. If an exposure has occurred the asymptomatic exposed residents should } \\
\text { be moved out and placed in a private room on appropriate COVID-19 } \\
\text { precautions (from each other and others) because they are potentially } \\
\text { already infected and incubating. }\end{array}$ \\
\hline $\begin{array}{l}\text { 5. If at all possible, residents should not be moved from a floor with COVID-19 } \\
\text { cases to a floor without COVID-19 cases (regardless of the individuals } \\
\text { COVID-19 swab status). }\end{array}$ \\
\hline $\begin{array}{l}\text { Canada, COVID-19 precautions include droplet and contact precautions, but local } \\
\text { uidance should be followed. } \\
\text { ligh-risk exposure defined as sustained ( }>15 \mathrm{~min}) \text {, unmasked contact with a confirmed or } \\
\text { Ispected COVID-19 case during the } 2 \mathrm{~d} \text { prior to symptom onset until day } 8 \text { after symptom } \\
\text { sset. }{ }^{6}\end{array}$ \\
\hline
\end{tabular}

\section{Acknowledgments.}

Financial support. No financial support was provided relevant to this article.

Conflicts of interest. All authors report no conflicts of interest relevant to this article.

\section{References}

1. Comas-Herrera A, Zalakaín J, Litwin C, et al. Mortality associated with COVID-19 outbreaks in care homes: early international evidence. LTC covid.org website. https://tccovid.org/2020/04/12/mortality-associated-withcovid-19-outbreaks-in-care-homes-early-international-evidence/. Published June 26, 2020. Accessed October 25, 2020.

2. McMichael TM, Currie DW, Clark S, et al. Epidemiology of COVID-19 in a long-term care facility in King County, Washington. N Engl J Med 2020;382: 2005-2011.

3. Brown KA, Jones A, Daneman N, et al. Association between nursing home crowding and COVID-19 infection and mortality in Ontario, Canada. MedRxiv 2020. doi: 10.1101/2020.06.23.20137729.

4. Rapid review: What is the effectiveness of cohorting virus-positive residents to shared rooms in care facilities? National Collaborating Centre for Methods and Tools website. http://www.nccmt.ca/knowledgerepositories/covid-19-evidence-reviews. Published June 26, 2020. Accessed October 25, 2020.

5. COVID-19 reference document for symptoms, version 4.0. Ontario Ministry of Health website. http://www.health.gov.on.ca/en/pro/programs/publichealth/ coronavirus/docs/2019_reference_doc_symptoms.pdf. Published May 14, 2020. Accessed October 25, 2020.

6. Boulware DR, Pullen MF, Bangdiwala AS, et al. A randomized trial of hydroxychloroquine as post-exposure prophyalxis for COVID-19. N Engl J Med 2020;383:517-525.

\title{
Frequency of coronavirus disease 2019 (COVID-19) symptoms in healthcare workers in a large health system
}

\author{
Jason H. Malenfant MD, MPH${ }^{1}$ (1), Caitlin N. Newhouse $\mathrm{MD}^{2}$ and Alice A. Kuo MD, PhD, MBA ${ }^{3}$ \\ ${ }^{1}$ Public Health \& Preventive Medicine Program, David Geffen School of Medicine, University of California, Los Angeles (UCLA), Los Angeles, California, \\ ${ }^{2}$ Division of Pediatric Infectious Diseases, David Geffen School of Medicine, University of California, Los Angeles (UCLA), Los Angeles, California and ${ }^{3}$ Division \\ of Medicine-Pediatrics, David Geffen School of Medicine, University of California, Los Angeles (UCLA), Los Angeles, California
}

To the Editor-Since the early phases of the coronavirus disease 2019 (COVID-19) epidemic across the United States, identifying and tracking healthcare worker (HCW)-to-HCW transmission

Author for correspondence: Jason H. Malenfant, E-mail: Jmalenfant@mednet.ucla.edu Cite this article: Malenfant JH, Newhouse CN, and Kuo AA. (2021). Frequency of coronavirus disease 2019 (COVID-19) symptoms in healthcare workers in a large health system. Infection Control \& Hospital Epidemiology, 42: 1403-1404, https:// doi.org/10.1017/ice.2020.1297 has been a major priority given the risk of exposing other colleagues, exposing vulnerable patients, and issues of limited staffing. Policy guidance regarding symptomatic screening for exclusion from work to mitigate transmission has not evolved much over the course of the pandemic to date.

From March 20 through April 10, 2020, a total of 2,193 severe acute respiratory coronavirus virus 2 (SARS-CoV-2) tests were ordered for HCWs in our institution, and $174 \mathrm{HCW}$ in our health

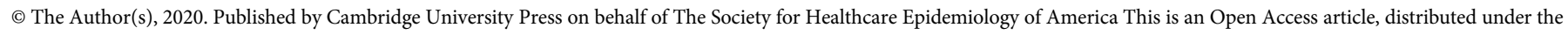

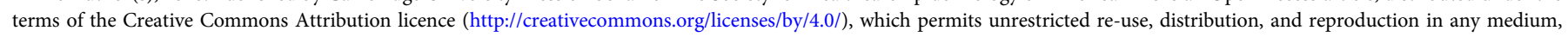
provided the original work is properly cited. 